\title{
The Three-Dimensional Structure of
}

\section{Transatlantic African Dust Transport: A New Perspective from CALIPSO LIDAR Measurements}

\author{
Dong Liu, ${ }^{1}$ Yingjian Wang, ${ }^{1}$ Zhien Wang, ${ }^{1,2}$ and Jun Zhou ${ }^{1}$ \\ ${ }^{1}$ Key Laboratory of Atmospheric Composition and Optical Radiation, Anhui Institute of Optics and Fine Mechanics, \\ Chinese Academy of Sciences, Hefei, Anhui 230031, China \\ ${ }^{2}$ Department of Atmospheric Science, University of Wyoming, Laramie, WY 82072, USA
}

Correspondence should be addressed to Dong Liu, dliu@aiofm.ac.cn

Received 20 January 2012; Revised 17 August 2012; Accepted 23 August 2012

Academic Editor: Achuthan Jayaraman

Copyright () 2012 Dong Liu et al. This is an open access article distributed under the Creative Commons Attribution License, which permits unrestricted use, distribution, and reproduction in any medium, provided the original work is properly cited.

\begin{abstract}
The lack of information on the vertical distribution of dust, in turn, results in large uncertainties when attempting to evaluate the impacts of dust on climate processes. We analyzed over two years of LIDAR measurements from NASA's CALIPSO and CloudSat satellites to document the vertical pathways of transatlantic transport of Saharan dust. Our analysis overcomes the limitations of quantitative dust detections with passive satellite measurements over land and low clouds and provides the fine vertical resolved structures. The results show the strong seasonal shift in dust source regions and transportation pathways due to the meteorological and thermodynamical conditions, which also control the dust vertical distribution as well as the depth of the dust layer. The dust layer top descending rates of $35 \mathrm{~m} /$ degree in summer, $25 \mathrm{~m} /$ degree in autumn and spring, and $10 \mathrm{~m} /$ degree in winter are found, respectively, while the dust is being transported across the Atlantic. Comparison with the model simulation highlights the potentials of dust observations using CALIPSO LIDAR. The observed seasonal dependence of these pathways gives new insights into the transport of the Saharan dust and provides important guidance for simulations of the production and transport of the global dust aerosol.
\end{abstract}

\section{Introduction}

Mineral dust is mainly generated from the continents and can be transported both horizontally and vertically into the atmosphere and affect vast area on the earth. Mineral dust plays an important role in climate processes by affecting radiation $[1,2]$, modifying cloud and precipitation processes by acting as cloud condensation nuclei $(\mathrm{CCN})$, giant $\mathrm{CCN}$ (GCCN), and effective ice nuclei (IN) [3-8]. Also mineral is an important source of nutrition which modulates a variety of marine biogeochemical processes [9]. However, among different types of aerosols, there are large uncertainties in dust sources, sinks, and their long-range transports $[10,11]$.

The Sahara is a primary source of dust, the majority of which is transported westward across the Atlantic to the Southeastern United States, the Caribbean Sea, and South America [12-14]. African dust and its transport have been documented by several passive remote sensors, for example, the Advanced Vary High Resolution Radiometer (AVHRR), Meteosat, Total Ozone Mapping Spectrometer (TOMS), and Moderate Resolution Imaging Spectroradiometer (MODIS) [15-18]. Modeling and observation results also suggest that Saharan dust and dust containing Sahara Air Layer (SAL) could impact the hurricane formation and evolution in the region of the North Atlantic $[19,20]$. Although our knowledge of the properties of Saharan dust, its transport, and impact has improved dramatically over the last three decades, the transatlantic transport of dust remains poorly understood, particularly its vertical distribution. For example, among AeroCom models (http://nansen.ipsl.jussieu.fr/AEROCOM), global and annual average dust mass fractions of total mass above $5 \mathrm{~km}$ altitude range from less $5 \%$ to close $30 \%$ [10]. Our limited understanding results from the inherent inability of passive sensors to provide vertically resolved measurements over large scales. The lack of information on the vertical 

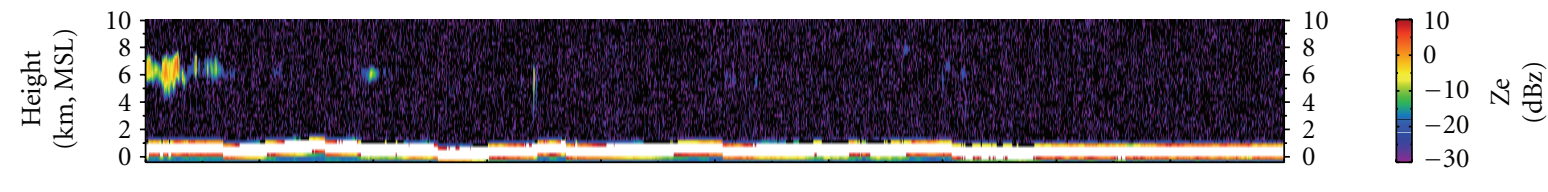

(a)

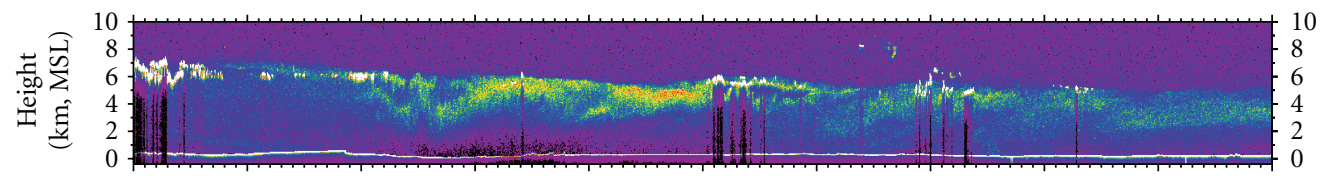

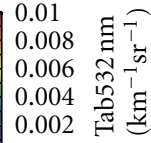

(b)
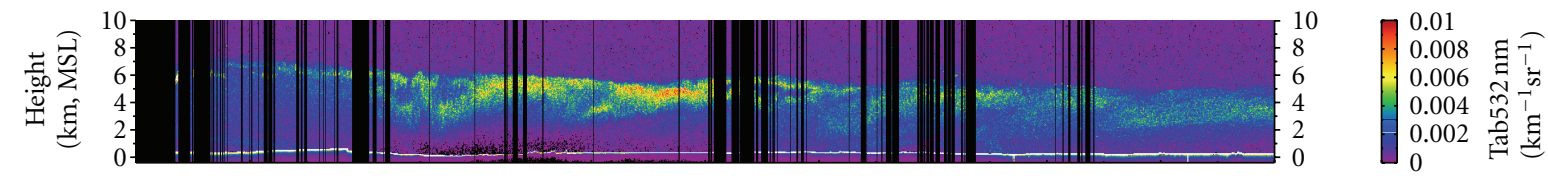

(c)

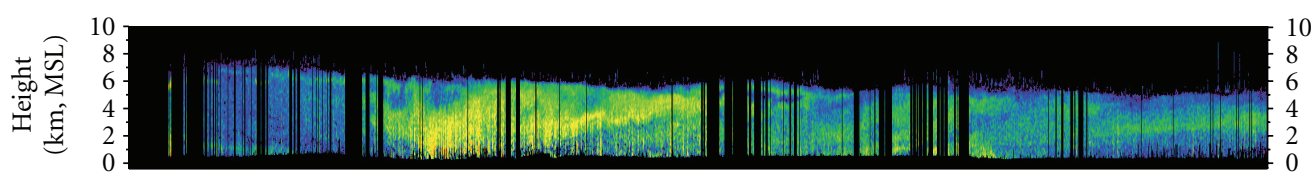

(d)

FIgURE 1: A retrieval example of dust extinction coefficient profile.

distribution of dust, in turn, results in large uncertainties when attempting to evaluate the impacts of dust on climate processes $[1,4]$.

Multiyear polarization LIDAR measurements from CALIPSO satellite provide new insights into the vertical distribution of dust on a global scale $[14,21]$. An approach was developed to provide vertical extinction and mass mixing ratio distribution based on CALIPSO LIDAR measurements. With these data we show a $3 \mathrm{D}$ view of across Atlantic dust transport and discuss their associations with largescale dynamics. We also compare with model simulations to illustrate major issues in simulated dust vertical distributions. Section 2 provides details of data analyses. Results and discussions are presented in Section 3. Finally, a brief summary is given in Section 4.

\section{Dataset and Methodology}

The CALIPSO and CloudSat satellites were launched together in April 2006 to join in the A-Train constellation and have been acquiring data since June 2006. The key instrument in the CALIPSO satellite payload is the CloudAerosol LIDAR with Orthogonal Polarization (CALIOP) [21]. CALIOP provides high vertical resolution profiles of aerosols and clouds (especially optically thin clouds) globally. The vertical and horizontal resolutions of the CALIOP are 30 and $333 \mathrm{~m}$ below $8.2 \mathrm{~km}$, and 60 and $1000 \mathrm{~m}$ between 8.2 and $20.2 \mathrm{~km}$, respectively. CloudSat carried the first space borne cloud radar-a 94.05 GHz Cloud Profiling Radar (CPR) with sensitivity of $-30 \mathrm{dBZ}$ [22]. The CPR measurements provide radar reflectivity $(\mathrm{Ze})$ profiles with a vertical resolution of
$240 \mathrm{~m}$ and a footprint of $1.4 \mathrm{~km} \times 1.8 \mathrm{~km}$ (cross and along track). Due to their different wavelengths, CPR and CALIOP complement with each other well to provide global threedimensional aerosol and cloud structure [23].

Taking the advantage of the synergy of the CALIPSO and CloudSat satellites, the CALIOP L1B profiles are collocated to CloudSat radar footprints based on their surface location. A section of collocated CPR and CALIOP measurements with dust layer and clouds is presented in Figures 1(a) and 1(b). Although CALIOP measurement itself can be used to separate aerosol and clouds, optically thick aerosol layers, such as dust layers over the dust source regions and smoke layers, are often misclassified as clouds [14, 24, 25]. However, these geometrically and optically thick aerosol layers have Ze values much lower than the CPR detection limit due to their small particle sizes. For clouds with a similar geometrical thickness and cloud temperature, the layer maximum $\mathrm{Ze}$ is often over $-10 \mathrm{dBZ}$ [26]. With the additional Ze profile, we can reduce the occurrence of this misclassification. Figure 1(c) shows identified aerosol layer by removing cloudy profiles (indicated with black lines) with CALIOP and CPR measurements. Optically thick high and middle clouds can significantly attenuate CALIOP signals. Therefore, it is challenging to reliably identify aerosol layers below these clouds. In this study, aerosol layers indentified under cloud-free conditions, in conjunction with optically thin cirrus, or above low clouds (cloud top height $<3 \mathrm{~km}$, above ground level) are used for further analyses.

Dust aerosols have higher linear depolarization ratios (the ratio of perpendicular to parallel polarization components measured by a LIDAR) than the other types of 
aerosols due to dust nonspherical shape, which can be used to distinguish them from other types of aerosols [14, 2729]. In this study, dust layers are first identified with a threshold method based on 1-km layer-averaged volume depolarization ratio (VDR), defined as the ratio of layer integrated perpendicular to parallel components at $532 \mathrm{~nm}$ based on the horizontal $1.5-\mathrm{km}$ averaged level $1 \mathrm{~B}$ data. As discussed in detail by Liu et al. [14], VDR $>0.06$ is used as a threshold for identifying dust layers and has been applied to the nighttime CALIPSO measurements during June 2006 through August 2008 to derive the vertical distribution of dust layers. With 1-km layer dust detection results, dust layer base and top heights are further refined [14]. The same definition of dust occurrence as Liu et al. [14] is used in this study.

Figure 1(d) gives the retrieved dust extinction coefficients based on Fernald backward integration method [30] combined with our proposed constrained-iteration scheme. Fernald method is often used to retrieve aerosol extinction profile which has both backward and forward integration algorithms. The backward integration is often adopted by the ground-based LIDAR while forward integration method for the space-borne one. For the atmospheric aerosol with the larger optical depth, the Fernald forward integration can produce larger errors because of the divergence. But here we apply backward integration algorithm to the CALIOP profile and constrain the retrieval iteration taking the advantage of the calibration of CALIOP using the averaged molecular backscatter between 30 and $34 \mathrm{~km}$ altitude on $532 \mathrm{~nm}$ wavelength [21]. Here is our proposed scheme: first, given an arbitrary extinction coefficient to the dust base, using the Fernald backward integration method, one can retrieve the extinction coefficients at $532 \mathrm{~nm}$ wavelength above the dust base, and the optical depth above the dust base can be obtained, recorded as $\mathrm{OD}_{\mathrm{BW}}$. Second, since CALIOP is well calibrated at this wavelength, the difference between the initial arbitrary extinction coefficient and the attenuated backscatter coefficient at the dust base can also be used to calculate the attenuation above the dust base thus obtaining the optical depth, recorded as $\mathrm{OD}_{\mathrm{AT}}$. Third, one can adjust the initial extinction coefficient at the dust base to start the iteration till these two optical depths are equal (in practice, assuming the absolute difference between $\mathrm{OD}_{\mathrm{BW}}$ and $\mathrm{OD}_{\mathrm{AT}}$ is smaller than 0.05). The LIDAR ratio of the dust aerosol uses the typical value of $40 \mathrm{Sr}$ suggested by CALIOP [29].

A comparison of the retrieved dust optical depths with a method developed by $\mathrm{Hu}$ et al. [31] with CALIOP ocean surface returns is presented in Figure 2. It clearly shows [that dust optical depths from the approach we proposed are consistent $\mathrm{Hu}$ et al. with a mean bias about 0.05.] Considering uncertainties in $\mathrm{Hu}$ et al. due to errors in estimated near surface wind speeds used to estimate two-way transmittance and in neglecting dust in the marine boundary layer, the agreement between two is very good and we can use extinction coefficients confidently for further analyses.

One application of dust extinction coefficient is to estimate dust mass concentration, which provides a more direct way to compare with model dust simulation. The specific extinction coefficient (the ratio of the extinction

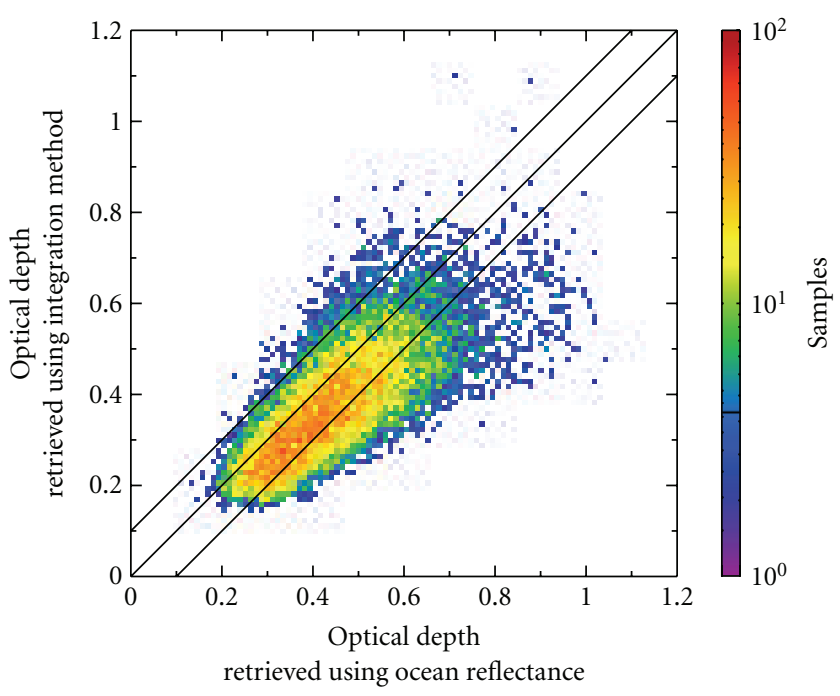

FIGURE 2: Comparison of dust layer optical depths with a method discussed in this paper (see text for more information) and with CALIOP surface returns over oceans [31]. The three solid lines are the $1: 1$ line and \pm 0.1 lines.

coefficient to mass) is used to convert extinction coefficient to mass concentration of dust which has been reported in many literatures. Maring et al. [32] derived $0.5 \mathrm{~m}^{2} / \mathrm{g}$ near Africa and $0.6 \mathrm{~m}^{2} / \mathrm{g}$ in Barbados and showed a small dust size distribution change when transported across the Atlantic. Chin et al. [33] used $0.8 \mathrm{~m}^{2} / \mathrm{g}$ for dust in the model simulations. Moulin et al. [34] reviewed dust models giving $0.6-0.8 \mathrm{~m}^{2} / \mathrm{g}$. Based on these published results and calculations with recent in situ dust size distributions, we decided to use $0.7 \mathrm{~m}^{2} / \mathrm{g}$ in this study with an uncertainty about $30 \%$.

\section{Results and Discussions}

3.1. Horizontal Dust Distributions. The height resolved seasonal dust occurrence maps (in $1^{\circ} \times 1^{\circ}$ grid box) over $100^{\circ} \mathrm{W}$ to $30^{\circ} \mathrm{E}$ and $15^{\circ} \mathrm{S}$ to $45^{\circ} \mathrm{N}$ are presented in Figure 3, which clearly show seasonal variations in the horizontal pathways of cross-Atlantic African dust transport. CALIPSO dust samples over Africa are mainly observed in cloudfree conditions or in conjunction with optically thin cirrus, while dust samples over the ocean are observed primarily in conjunction with low clouds. Comparing results without considering dust over low clouds (see Figure 2 in Liu et al. [14]), significant dust aerosols are transported across the Atlantic above low-level clouds. Detection of dust layers above low clouds is extremely difficult for passive sensors. Thus, CALIOP measurements provide the most reliable dust detection over regions with high occurrences of low clouds [26].

Figure 3 clearly shows that the transatlantic African dust occurs all year long, but June-July-August (JJA) is the most active season. During JJA, over a large area of the Northern African continental has dust occurrence over $80 \%$, and the majority of them have dust top heights reach above $4 \mathrm{~km}$. 


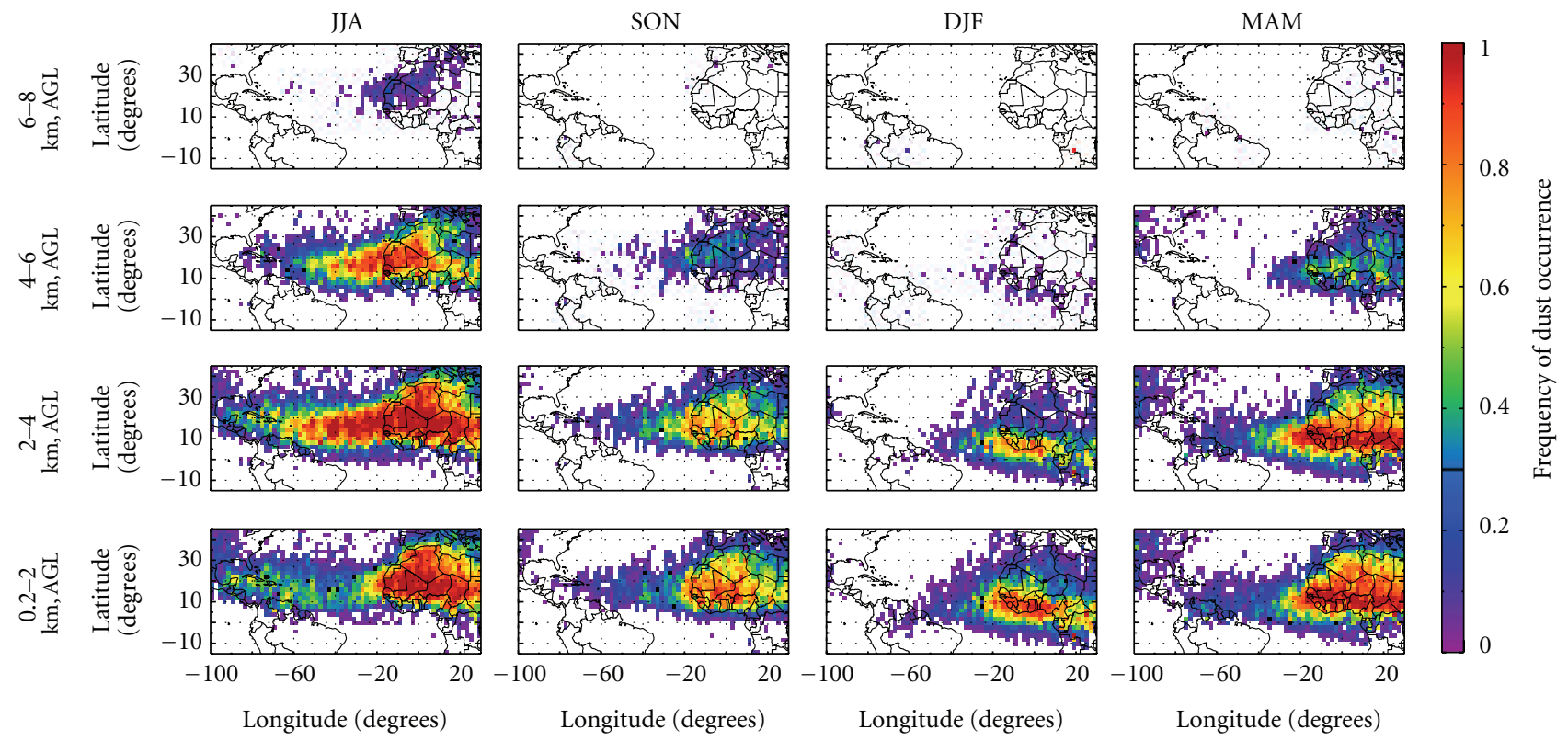

FIGURE 3: The height resolved seasonal maps of dust occurrences over the Atlantic Ocean and surrounding regions derived from collocated CALIOP and CPR measurements.

Dense dust layers during JJA can reach above $6 \mathrm{~km}$. MarchApril-May (MAM) is the second most active dust season with high occurrence areas concentrated over a smaller region than JJA. Compared with JJA, there are significant less dense dust layers reaching above $4 \mathrm{~km}$ during MAM. DecemberJanuary-February (DJF) is the quietest period with a small high occurrence area close to equator with most dust layer concentrated below $2 \mathrm{~km}$ overland.

The high dust occurrence regions over the Atlantic indicate the dust transport pathway. During JJA, dust aerosols are transported the furthest west. Over the most area of the west Atlantic between $10-30^{\circ} \mathrm{N}$, there is over $40 \%$ chance to find dust layer below $4 \mathrm{~km}$. Compared with JJA and SeptemberOctober-November (SON), dust-transporting pathways shift southwards $\sim 10^{\circ}$ in DJF and MAM. During DJF, only limited dust storms are transported across the Atlantic, and dust aerosols are transported southward after reaching the west coast of the Atlantic while they are transported northward in the other seasons. It is clear that the vertical ranges of dust transported across the Atlantic depend on the dust vertical distributions of dust aerosol in the source regions. With the zonal dust cross-sections, this feature will be discussed further in the next subsection.

3.2. Vertical Dust Distributions. To illustrate the vertical pathway of African dust across the Atlantic Ocean, all dusty profiles are used to calculate the zonal cross-sections of vertical dust distributions as illustrated in Figure 3. The mean vertical dust occurrence is calculated as the ratio of total dust cases observed at a given height range to the total dust case over the region within a 2-degree longitude bin based on profiles containing dust layers below $8 \mathrm{~km}$. The vertical resolution of the calculation is $60 \mathrm{~m}$. Thus, a $100 \%$ occurrence in Figure 4(a) indicates that dust always occurs in this height range when a dust layer is transported into the region.

The vertical distribution of dust over source regions (east of $-18^{\circ}$ longitude) shows strong seasonal variations. During JJA, most dust layers have tops above $5 \mathrm{~km}$, while the majority of dust layers lie below $4 \mathrm{~km}$ during other seasons. Except MAM, mean dust tops generally increase westward but with noticeably different slopes. As these layers are transported westward over the eastern edge of the Atlantic Ocean, their bases are gradually lifted due to strong inversions near the top of the marine boundary layer. The corresponding longitude of the maximum dust layer base height is about $25^{\circ} \mathrm{W}, 30^{\circ} \mathrm{W}$, and $35^{\circ} \mathrm{W}$ in JJA, SON, and MAM, respectively. The net effect of the changes in layer base and top heights is to confine most dust layers to altitudes between 2 and $4 \mathrm{~km}$ as they are transported further west. Although most dust layers are lifted above the marine boundary layer, during winter a greater proportion of dust is transported into the marine boundary layer near the west coast of Africa.

The fates of dust aerosols are determined by dry deposition, wet removal, cloud microphysical processes, and dynamics $[35,36]$. The mean dust layer top slowly descends across the Atlantic at rates of about $35 \mathrm{~m} /$ degree in JJA, $25 \mathrm{~m} /$ degree in SON and MAM, and $10 \mathrm{~m} / \mathrm{deg}$ in DJF, mainly due to dry deposition and large-scale subsidence. Dust layers approaching the Caribbean Sea and the South American coast could either be lifted to higher altitudes or brought down into the boundary layer as a result of more vigorous convection. LIDAR data from the first two and half years shows large interannual variability in the vertical distribution of dust over these regions. Dust particles lifted to high altitudes and colder temperatures can act effective ice nuclei, thereby affecting cloud properties and precipitation 

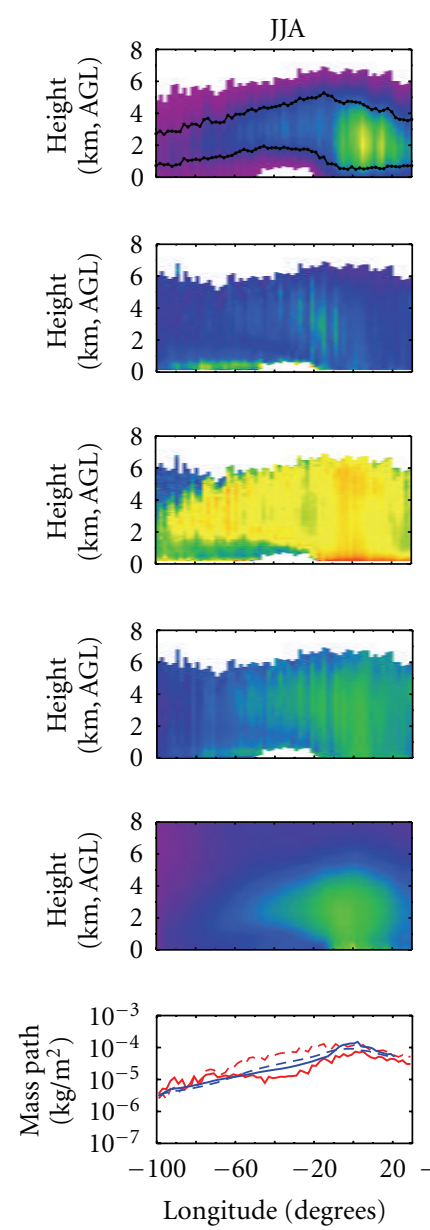

CALIOP/CALIPSO

DEAD model
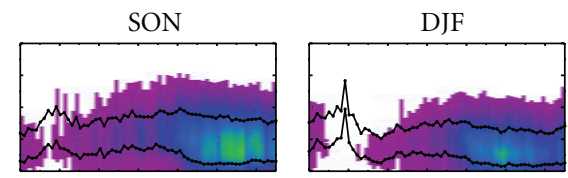

(a)
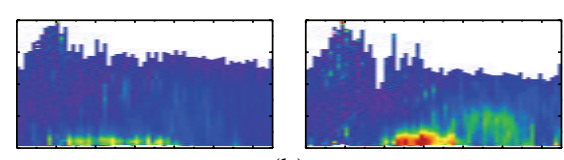

(b)
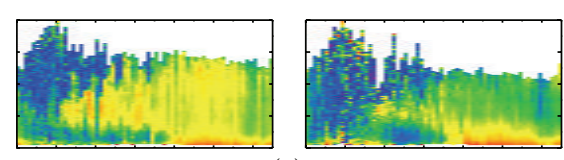

(c)
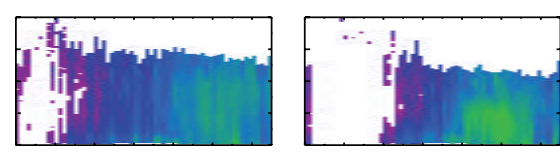

(d)
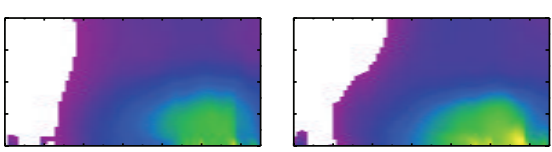

(e)
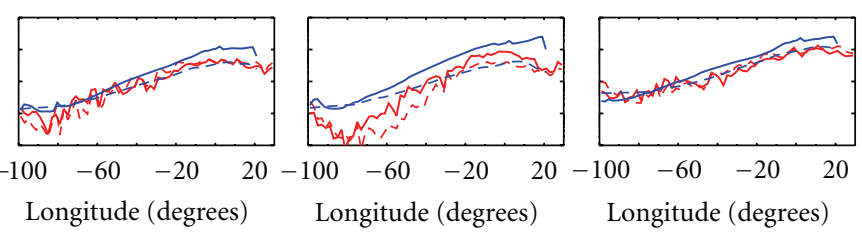

Longitude (degrees)

Longitude (degrees)
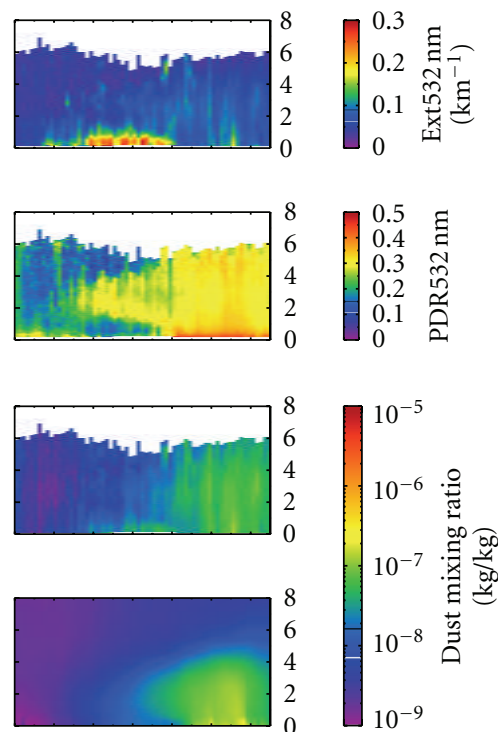

(f)

FIgURE 4: Vertical structures of cross-Atlantics Sahara dust measured by CALIPSO LIDAR and comparison with the model simulation (averaged in the grid box latitude from $-15^{\circ}$ to $45^{\circ}$ and longitude from $-100^{\circ}$ to $30^{\circ}$ ). (a) frequency of dust aerosols occurrence with mean dust layer base and top heights, (b) dust extinction coefficient, (c) dust aerosol particle depolarization ratio, (d) dust mass mixing ratio (assuming the specific extinction coefficient is $0.7 \mathrm{~m}^{2} \mathrm{~g}^{-1}$ ), (e) dust mixing ratio obtained from the DEAD dust model (1990-1999 ten year average), (f) dust column mass path.

generation, while those entrained into the boundary layer are more efficiently removed through deposition to the surface, attachment to cloud drops, or coalescence scavenging.

Along the pathway, the variations of vertical dust distributions reflect the dust layer thickness changes. Over the ocean, the dust occurrence magnitudes decrease significantly as dust is transported further west. This reflects that the dust layer thicknesses decrease along the transportation pathway, which could be caused by the horizontal SAL expansion or mixing across SAL vertical boundaries. Although dust layer thicknesses between JJA and MAM are similar over the land, thick dust layers are transported further west in JJA than in MAM.

Dust aerosol extinction coefficient and particle depolarization ratio show dust loading and particle shape variations along the transportation. Due to large dust particle size, high dust extinction $(532 \mathrm{~nm})$ could indicate regions with major dust storms. It clearly shows that these regions with high dust extinctions are not exactly correlated with high dust occurrence regions. Therefore, everyday boundary layer dust aerosols contribute significantly to the high occurrence of dust aerosols overland. This is consistent with yearround dusty boundary layer observed in West Africa with sophisticated ground-based instrumentation [37]. Overland, DJF has the highest mean extinction coefficient, although the dust layers are shallower during DJF than the other seasons. SON has the lowest mean extinction coefficient overland.

The particle depolarization ratios given in Figure 4(c) are controlled by two major factors: dust particle shape and size and mixing of dust with different aerosols. Over land, highest depolarization ratios are typically found near surface, which could be mainly due to large irregular dust particles. Other 
than DJF, vertical particle depolarization ratios have small variations with height, which indicates that the dust layer is well mixed. During DJF, particle depolarization ratios above $2 \mathrm{~km}$ are noticeably smaller than the aerosols below, which could be the results of different mixings of dust with other aerosols or vertical particle size and shape stratifications within the dust layer. The seasonal differences of dust transport through marine boundary layers are illustrated more clearly with dust occurrence and depolarization. The particle depolarization ratios revealed that dusty layers can push a few hundred kilometers west over the ocean before significantly mixed with sea salts (indicated with high extinction coefficients and low particle depolarization ratios) during DJF and MAM. Over ocean, high dust occurrence regions are coincident with high particle depolarization regions as well. Therefore, these regions are good indicators for the positions of unmixed SAL cores when the SALs propagate across the Atlantic. On the other hand, it suggests that strong mixings happen along the dust transportation, which could be very difficult for the model to simulate.

To see how the model captures these general features revealed with CALIOP measurements, dust extinction coefficients are converted to mass mixing ratio for model simulation comparisons. Figure 4(d) shows the dust mass mixing ratio estimated from retrieved extinctions. Although the uncertainties can be as high as $30 \%$ mainly due to the selection of specific extinction coefficient, the main heightlongitude structure is reliable. It is well known that there are large differences in simulated dust mass distributions among state-of-art models [34, 36, 38, 39]. Thus, extended evaluations of these models are out of the scope of this paper, and we only use one published dust modeling result to highlight the potentials of using CALIOP observations to identify the model simulation weaknesses [36]. Figures 4(d)-4(f) clearly show that the DEAD dust model captures the general seasonal variations of dust vertical and horizontal distributions, but there are several noticeable differences. First, the DEAD model predicts more dust below $2 \mathrm{~km}$ than estimations from observations. Second, there are noticeable differences in longitude distributions of dust distributions overland. Although this can be potentially caused by different meteorology conditions, but CALIOP and MODIS observations indicated limited interannual variations [18]. Third, there are differences in how far dust aerosols are transported westerly. Model simulated dust aerosols are transported further west than the observations. Fourth, model simulations show that significant aerosols are transported above $6 \mathrm{~km}$, but CALIOP measurements have difficulties to detect these dust aerosols due to low signal-to-noise ratio for weak aerosol layers or challenges in separating dust with optically thin ice clouds at colder temperatures. Due to the important roles of dust aerosols at these high elevations through both mixed-phase and ice cloud microphysical processes, improved dust detections for CALIOP measurements or new dust measurements over tropical upper troposphere are needed.

3.3. 3-Dimensional Dust Layer Top Variations. To further illustrate the advantage of active measurements, grid-box

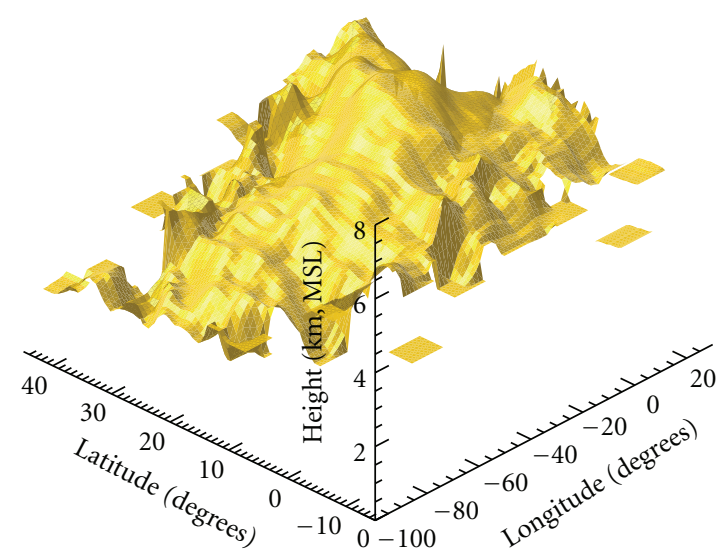

Figure 5: A surface plot of grid mean dust layer top height distributions.

mean dust layer top distribution during JJA is illustrated in Figure 5. As the dust layer is transported west across the Atlantic Ocean, the dust layer top generally decreases further west, but there are interesting latitude variations at a given longitude. The center part of dust layer shows a smooth top variation with a higher top near the center and decreases to both sides. As illustrated in Figure 6, the southern side of dust layer is bounded by the Inter-Tropical Convergence Zone (ITCZ), and the northern side of the dust layer is bounded by strong westerly flow. Large top variations near the boundaries in Figure 6 clearly indicate that strong vertical mixings occur at these boundaries.

3.4. Dynamical Control of Dust Transport. Many studies explored the processes controlling dust emitted from Africa desert regions and their transportation in the atmosphere $[18,36,40,41]$. However, these studies are limited with the available data. With passive sensor retrieved optical depths over water, Moulin et al. [34] showed the importance of large-scale climatic control on the dust export by changing precipitation and atmospheric circulations over the regions of dust mobilization and transport. Using a satellite-derived dust index, Engelstaedter and Washington [41] concluded that the dry convection associated with an increase in the occurrence of small-scale high-wind events and vertical velocity are the main processes controlling the annual dust cycle at the West African dust sources. With better dust detection and quantitatively estimation capabilities of CALIOP over land and clouds, long-term CALIOP measurements will offer a new source data to understand the processes controlling African dust.

Based on the first three-year CALIOP data, Figure 6 shows the importance of dynamics in African dust transport. In Figure 6(a), seasonal dust occurrences are overplotted with the $850 \mathrm{mb}$ horizontal wind from NCEP/NCAR reanalysis data [42], which clearly show that the westward transport of African dust is strongly controlled by the prevailing easterlies. The southern bound of dust layer is limited to the positions of the ITCZ, which can be identified in Figure 6(d) as tropical regions with weak updraft velocities the over 

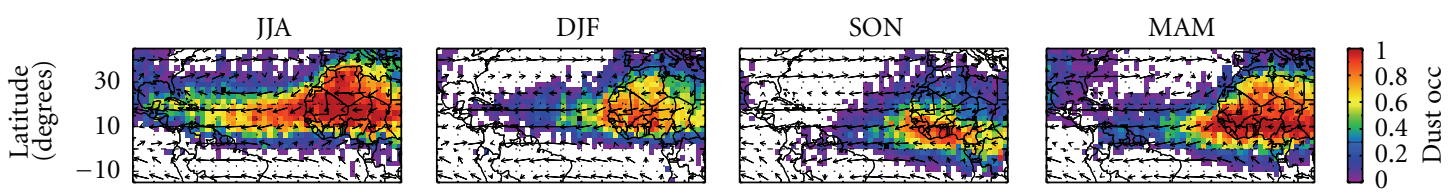

(a)
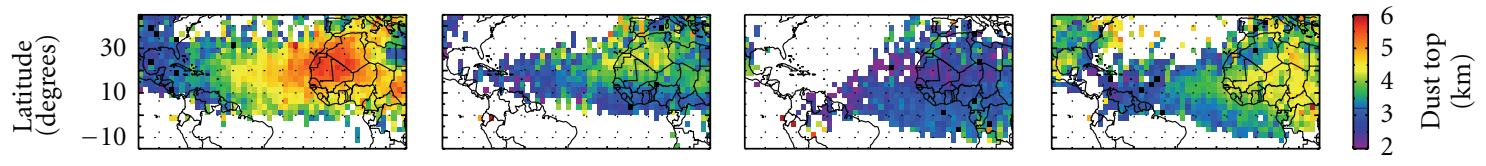

(b)
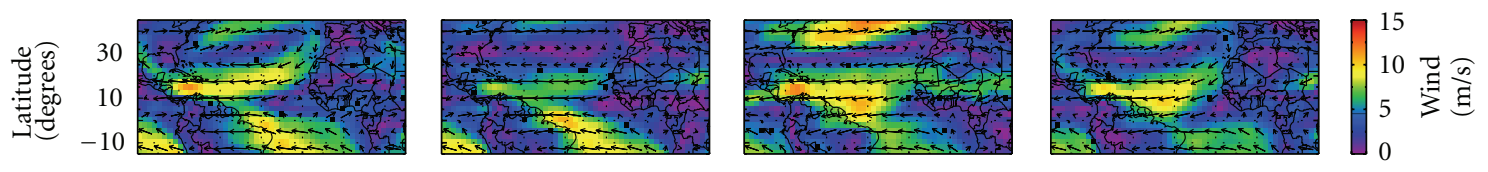

(c)
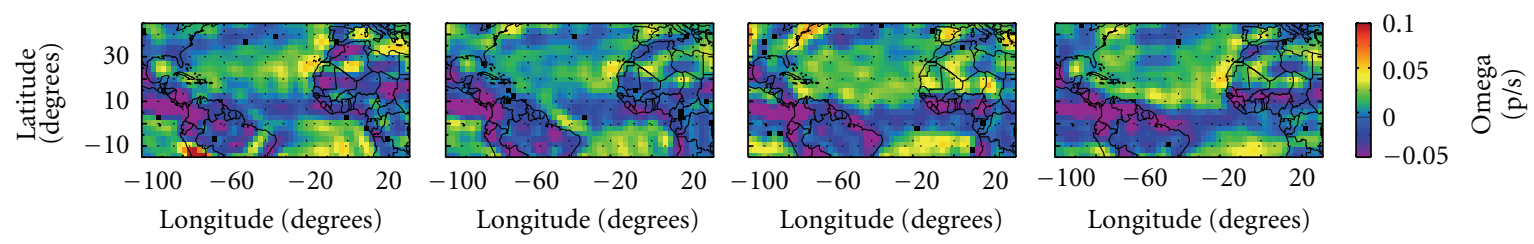

(d)

FIGURE 6: Meteorological control of the Sahara dust transportation (2.5 degrees by 2.5 degrees): (a) Frequency of dust aerosols occurrence overplotted with horizontal wind, (b) averaged dust layer top height (AGL), (c) wind speed and direction (1000 mb 850 mb), and (d) vertical velocity $(1000 \mathrm{mb} \sim 850 \mathrm{mb})$.

ocean and stronger updraft velocities over the land. The seasonal shifting of ITCZ and associated strong easterly wind zones determine the track of dust transportation across the Atlantic [40]. During DJF, strong updrafts over South America and high wind over the tropical east Atlantic bring significant African dust to the Amazon region, even though dust over the source regions is mainly confined below $2 \mathrm{~km}$ during this period.

Large-scale convergences and associated updrafts (see Figures 6(c) and 6(d)) overland are one of the important factors to control African dust aerosol production. As discussed by Engelstaedter and Washington [41], large-scale convergences favor dry convection developments and cause an increase in the occurrence of small-scale high-wind events to produce more dense dust storms. The updrafts associated with large-scale convergences not only support deep dust layer developments, but also increase dust lifetime by reducing gravity sedimentation [36]. During DJF, a narrow updraft band in the south of $10^{\circ} \mathrm{N}$ can be clearly identified in Figure 6(d), which collocates with high dust occurrence areas. Compared with DJF, there other three seasons have a more wide distributed dust overland, which could be attributed to multiple convergence zones developed in northern $10^{\circ} \mathrm{N}$. Due to strong solar heating, JJA has wide and stronger updraft zones which produces the deepest dust layer in all season.

\section{Summary}

Mineral dust plays an important role in the climate system processes by affecting radiation, modifying cloud and precipitation processes, and modulating a variety of marine biogeochemical processes. The Sahara is a primary source of dust, the majority of which is transported westward across the Atlantic to the Southeastern United States, the Caribbean Sea, and South America. However, there are large uncertainties in dust sources, sinks, and their long-range transports. To overcome the limitations of quantitative dust detections with passive satellite measurements over the land and low clouds, we use multiyear combined CALIPSO and CloudSat data to show three-dimensional dust distributions over the source regions and their transport pathways across the Atlantic.

To improve dense dust detection, CloudSat radar detected that clouds are used to together with CALIOP measurements to provide more reliable vertical resolved dust occurrence maps. The results show strong seasonal shifts in dust source regions and transportation pathways. Other than DJF, dust aerosols are produced over several large areas scattered across Africa, which result in a wide spread dust overland. These results confirm that both large-scale and small-scale meteorological conditions are important for dust emissions over Africa. The seasonal differences in meteorological and thermodynamical conditions also result 
in significant differences in dust vertical distributions overland with the deepest dust layer in JJA and the shallowest dust layer in DJF. Although the seasonal north-south shifts of dust bands across the Atlantic are linked with the movements of the ITCZ, the seasonal vertical pathways are also linked to many other factors. When dust aerosols are transported across the Atlantic, the mean dust layer top descends at different rates (about $35 \mathrm{~m}$ /degree in JJA, $25 \mathrm{~m}$ /degree in SON and MAM, and $10 \mathrm{~m} / \mathrm{deg}$ in DJF). The amount of dust transported below and above $2-\mathrm{km}$ also changes with seasons. JJA has more dust transported above $2 \mathrm{~km}$ and reached further west to impact large areas including the east coast of North America.

The extinction coefficients and particle depolarization ratio of dusty aerosols are also derived to understand dust distribution more quantitatively. Other than DJF, dust aerosols are vertically well mixed overland; however, there are significant horizontal variations. The spatial patterns of dust extinction coefficients and depolarization ratios indicate that the strong mixings occur as dust is transported across the Atlantic. These mixing processes could be challenging for models to simulate. Further studies with CALIOP and airborne measurements are needed to better understand these mixing processes.

To illustrate the potentials to use CALIOP measurements for dust transport model improvements, we use a specific extinction coefficient that is $0.7 \mathrm{~m}^{2} \mathrm{~g}^{-1}$ to convert dust extinction coefficients to dust mass mixing ratios, which are predicted by most models. As an example, observations are compared with DEAD simulated dust spatial distributions. It is clear that the DEAD dust model captures the general seasonal variations of dust distributions, but several noticeable model biases are identified for further improvements. Although there are up to $30 \%$ uncertainties in estimating dust mass loading from CALIOP measurements, it is very valuable to reduce larger intermodal spreads in dust simulations, especially on dust vertical distributions. With twowavelength CALIOP measurements, further improvements of dust mass loading estimations are possible. Because dust aerosols are efficient IN, validating and improving model simulations above $6 \mathrm{~km}$ require better observation capabilities for optically thin dust detection.

The general features of the vertical pathways of dust transport across the Atlantic demonstrate that African dust observed at surface sites within and along the eastern edge of the Atlantic is strongly affected by meteorological conditions. Therefore, surface observations of dust are not, by themselves, sufficient for evaluating simulations of transatlantic transport of African dust. Long-term observations from space-borne LIDARs, together with radiometer measurements, are key for understanding the production and transport of African dust and for improving its representation in the climate and weather models that are needed to quantify the impact of African dust on climate change.

\section{Acknowledgments}

This research is supported by the National Natural Science Foundation of China (no. 41075016) and the Major
State Basic Research Development Program of China (no. 2011CB403400). Z. Wang is supported by NASA Grant NNX07AQ83G and NNX10AN18G. The authors would like to thank CALIPSO PIs Dave Winkler and Charles Trepte, CloudSat PIs Graeme Stephens and Deborah Vane, and the CALIPSO/CloudSat data group. NCEP Reanalysis data was provided by the NOAA/OAR/ESRL PSD, Boulder, CO, USA, from their website at http://www.esrl.noaa.gov/psd/.

\section{References}

[1] I. N. Sokolik, "The spectral radiative signature of wind-blown mineral dust: implications for remote sensing in the thermal IR region," Geophysical Research Letters, vol. 29, no. 24, article 2154, 4 pages, 2002.

[2] H. E. Brindley and J. E. Russell, "An assessment of Saharan dust loading and the corresponding cloud-free longwave direct radiative effect from geostationary satellite observations," Journal of Geophysical Research D, vol. 114, no. 23, Article ID D23201, 2009.

[3] Z. Levin, E. Ganor, and V. Gladstein, "The effects of desert particles coated with sulfate on rain formation in the eastern Mediterranean," Journal of Applied Meteorology, vol. 35, no. 9, pp. 1511-1523, 1996.

[4] P. J. DeMott, K. Sassen, M. R. Poellot et al., "African dust aerosols as atmospheric ice nuclei," Geophysical Research Letters, vol. 30, 4, 1732 pages, 2009.

[5] K. Sassen, P. J. DeMott, J. M. Prospero, and M. R. Poellot, "Saharan dust storms and indirect aerosol effects on clouds: CRYSTAL-FACE results," Geophysical Research Letters, vol. 30, article1633, 2003.

[6] S. C. van den Heever, G. G. Carrió, W. R. Cotton, P. J. DeMott, and A. J. Prenni, "Impacts of nucleating aerosol on Florida storms - part I: mesoscale simulations," Journal of the Atmospheric Sciences, vol. 63, no. 7, pp. 1752-1775, 2006.

[7] C. H. Twohy, S. M. Kreidenweis, T. Eidhammer et al., "Saharan dust particles nucleate droplets in eastern Atlantic clouds," Geophysical Research Letters, vol. 36, no. 1, Article ID L01807, 2009.

[8] Q. L. Min, R. Li, B. Lin et al., "Evidence of mineral dust altering cloud microphysics and precipitation," Atmospheric Chemistry and Physics, vol. 9, no. 9, pp. 3223-3231, 2009.

[9] N. M. Mahowald, A. R. Baker, G. Bergametti et al., "Atmospheric global dust cycle and iron inputs to the ocean," Global Biogeochemical Cycles, vol. 19, Article ID GB4025, 2005.

[10] C. Textor, M. Schulz, S. Guibert et al., "Analysis and quantification of the diversities of aerosol life cycles within AeroCom," Atmospheric Chemistry and Physics, vol. 6, no. 7, pp. 17771813, 2006.

[11] IPCC, "Climate change 2007," in The Physical Science Basis, S. Solomon, D. Qin, M. Manning et al., Eds., Cambridge University Press, New York, NY, USA, 2007.

[12] J. M. Prospero, R. A. Glaccum, and R. T. Nees, "Atmospheric transport of soil dust from Africa to South America," Nature, vol. 289, no. 5798, pp. 570-572, 1981.

[13] J. S. Reid, H. H. Jonsson, H. B. Maring et al., "Comparison of size and morphological measurements of coarse mode dust particles from Africa," Journal of Geophysical Research D, vol. 108 , article 8593, 2003.

[14] D. Liu, Z. Wang, Z. Liu, D. Winker, and C. Trepte, "A height resolved global view of dust aerosols from the first year CALIPSO LIDAR measurements," Journal of Geophysical Research D, vol. 113, no. 16, Article ID D16214, 2008. 
[15] R. B. Husar, J. M. Prospero, and L. L. Stowe, "Characterization of tropospheric aerosols over the oceans with the NOAA advanced very high resolution radiometer optical thickness operational product," Journal of Geophysical Research D, vol. 102, no. 14, pp. 16889-16909, 1997.

[16] C. Moulin, C. E. Lambert, F. Dulac, and U. Dayan, "Control of atmospheric export of dust from North Africa by the North Atlantic Oscillation," Nature, vol. 387, no. 6634, pp. 691-694, 1997.

[17] J. M. Prospero, P. Ginoux, O. Torres, S. E. Nicholson, and T. E. Gill, "Environmental characterization of global sources of atmospheric soil dust identified with the Nimbus 7 Total Ozone Mapping Spectrometer (TOMS) absorbing aerosol product," Reviews of Geophysics, vol. 40, article 1002, 2002.

[18] Y. J. Kaufman, I. Koren, L. A. Remer, D. Tanré, P. Ginoux, and S. Fan, "Dust transport and deposition observed from the Terra-Moderate Resolution Imaging Spectroradiometer (MODIS) spacecraft over the Atlantic Ocean," Journal of Geophysical Research D, vol. 110, Article ID D10S12, 2005.

[19] K. M. Lau and K. M. Kim, "Cooling of the atlantic by saharan dust," Geophysical Research Letters, vol. 34, Article ID L23811, 2007.

[20] H. Zhang, G. M. McFarquhar, S. M. Saleeby, and W. R. Cotton, "Impacts of Saharan dust as CCN on the evolution of an idealized tropical cyclone," Geophysical Research Letters, vol. 34, no. 14, Article ID L14812, 2007.

[21] D. M. Winker, W. H. Hunt, and M. J. McGill, "Initial performance assessment of CALIOP," Geophysical Research Letters, vol. 34, Article ID L19803, 2007.

[22] G. L. Stephens, D. G. Vane, D. Tanelli et al., "The CloudSat mission: performance and early science after the first year of operation," Journal of Geophysical Research, vol. 113, Article ID D00A18, 2008.

[23] G. L. Stephens, "The CloudSat mission and the A-Train," Bulletin of the American Meteorological Society, vol. 83, pp. 1771-1790, 2002.

[24] M. Vaughan, S. Young, D. Winker et al., "Fully automated analysis of space-based LIDAR data: an overview of the CALIPSO retrieval algorithms and data products," in Laser Radar Techniques for Atmospheric Sensing, Proceedings of SPIE, pp. 16-30, September 2004.

[25] Z. Liu, M. Vaughan, D. Winker et al., "The CALIPSO LIDAR cloud and aerosol discrimination: version 2 algorithm and initial assessment of performance," Journal of Atmospheric and Oceanic Technology, vol. 26, no. 7, pp. 1198-1213, 2009.

[26] D. C. Leon, Z. Wang, and D. Liu, "Climatology of drizzle in marine boundary layer clouds based on 1 year of data from CloudSat and Cloud-Aerosol LIDAR and Infrared Pathfinder Satellite Observations (CALIPSO)," Journal of Geophysical Research D, vol. 114, no. 8, Article ID D00A14, 2009.

[27] K. Sassen, "LIDAR backscatter depolarization technique for cloud and aerosol research," in Light Scattering by Nonspherical Particles: Theory, Measurements, and Geophysical Applications, M. L. Mishchenko, J. W. Hovenier, and L. D. Travis, Eds., pp. 393-416, Academic Press, San Diego, Calif, USA, 2000.

[28] Z. Liu, A. Omar, M. Vaughan et al., "CALIPSO LIDAR observations of the optical properties of Saharan dust: a case study of long-range transport," Journal of Geophysical Research $D$, vol. 113, no. 7, Article ID D07207, 2008.

[29] A. H. Omar, D. M. Winker, C. Kittaka et al., "The CALIPSO automated aerosol classification and LIDAR ratio selection algorithm," Journal of Atmospheric and Oceanic Technology, vol. 26, no. 10, pp. 1994-2014, 2009.
[30] F. G. Fernald, "Analysis of atmospheric LIDAR observations: some comments," Applied Optics, vol. 23, pp. 652-653, 1984.

[31] Y. Hu, K. Stamnes, M. Vaughan et al., "Sea surface wind speed estimation from space-based LIDAR measurements," Atmospheric Chemistry and Physics, vol. 8, no. 13, pp. 35933601, 2008.

[32] H. Maring, D. L. Savoie, M. A. Izaguirre, L. Custals, and J. S. Reid, "Mineral dust aerosol size distribution change during atmospheric transport," Journal of Geophysical Research D, vol. 108, no. 19, article 8592, 2003.

[33] M. Chin, P. Ginoux, S. Kinne et al., "Tropospheric aerosol optical thickness from the GOCART model and comparisons with satellite and sun photometer measurements," Journal of the Atmospheric Sciences, vol. 59, no. 3, pp. 461-483, 2002.

[34] C. Moulin, F. Dulac, C. E. Lambert et al., "Long-term daily monitoring of Saharan dust load over ocean using Meteosat ISCCP-B2 data 2. Accuracy of the method and validation using Sun photometer measurements," Journal of Geophysical Research D, vol. 102, no. 14, pp. 16959-16969, 1997.

[35] P. Ginoux, M. Chin, I. Tegen et al., "Sources and distributions of dust aerosols simulated with the GOCART model," Journal of Geophysical Research D, vol. 106, no. 17, pp. 20255-20273, 2001.

[36] C. S. Zender, H. Bian, and D. Newman, "Mineral Dust Entrainment and Deposition (DEAD) model: description and 1990s dust climatology," Journal of Geophysical Research D, vol. 108, no. 14, article 4416, 2003.

[37] M. A. Miller and A. Slingo, "The ARM Mobile Facility and its first international deployment: measuring radiative flux divergence in West Africa," Bulletin of the American Meteorological Society, vol. 88, no. 8, pp. 1229-1244, 2007.

[38] P. Ginoux, J. M. Prospero, O. Torres, and M. Chin, "Longterm simulation of global dust distribution with the GOCART model: correlation with North Atlantic Oscillation," Environmental Modelling and Software, vol. 19, no. 2, pp. 113-128, 2004.

[39] C. Timmreck and M. Schulz, "Significant dust simulation differences in nudged and climatological operation mode of the AGCM ECHAM," Journal of Geophysical Research D, vol. 109, no. 13, Article ID D13202, p. D13202, 2004.

[40] J. M. Prospero and R. T. Nees, "Impact of the North African drought and El Nino on mineral dust in the Barbados trade winds," Nature, vol. 320, no. 6064, pp. 735-738, 1986.

[41] S. Engelstaedter and R. Washington, "Atmospheric controls on the annual cycle of North African dust," Journal of Geophysical Research, vol. 112, Article ID D03103, 2007.

[42] NCEP Reanalysis data are from the NOAA-CIRES Climate Diagnostics Center, http://www.cdc.noaa.gov/. 

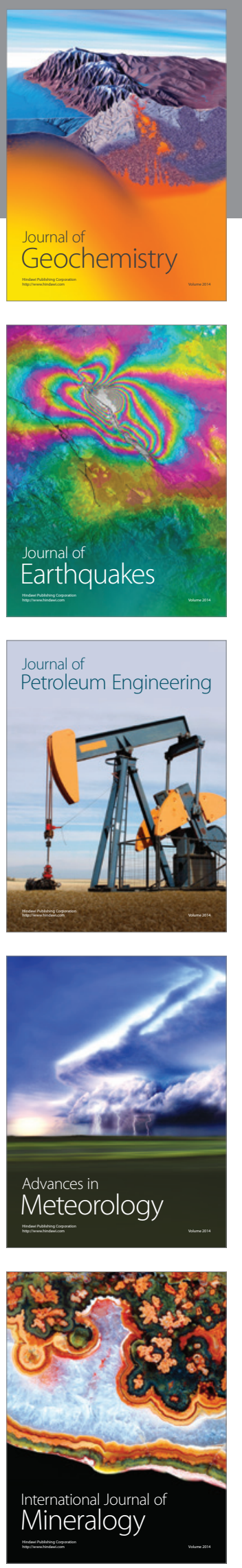
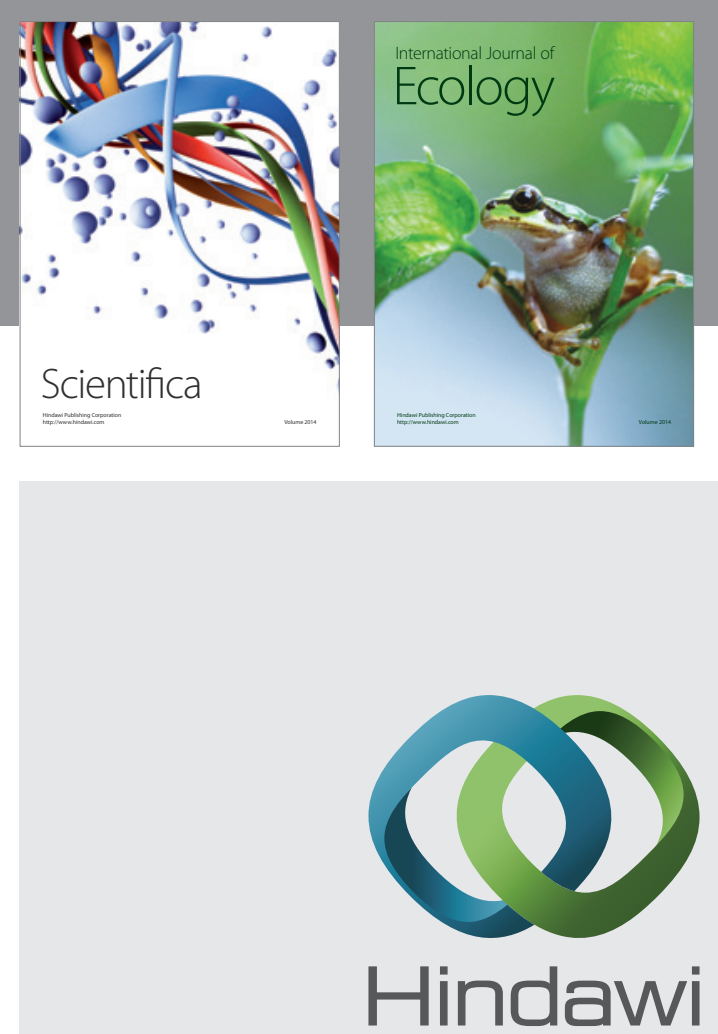

Submit your manuscripts at http://www.hindawi.com
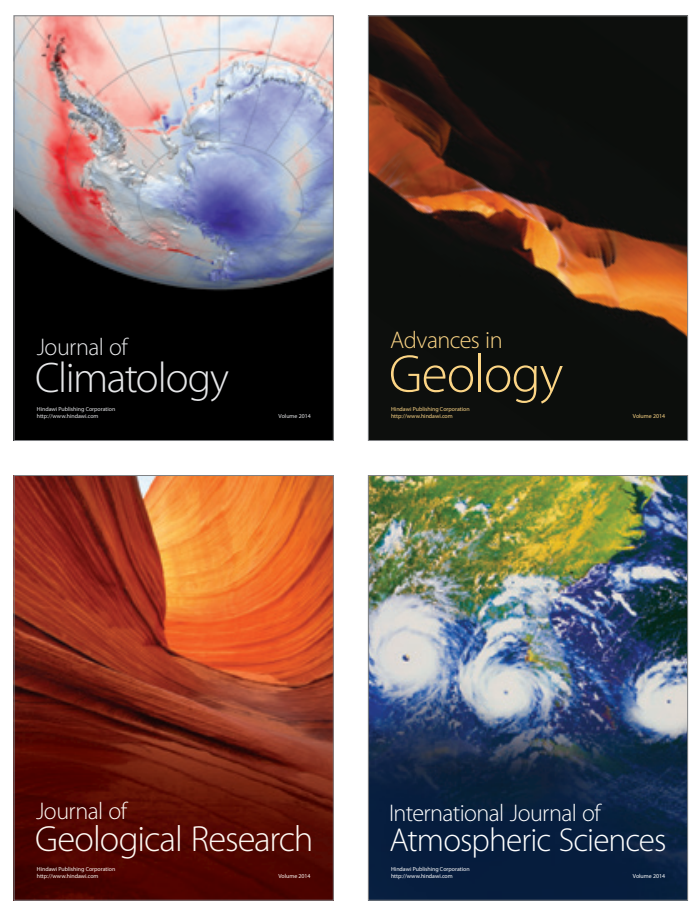
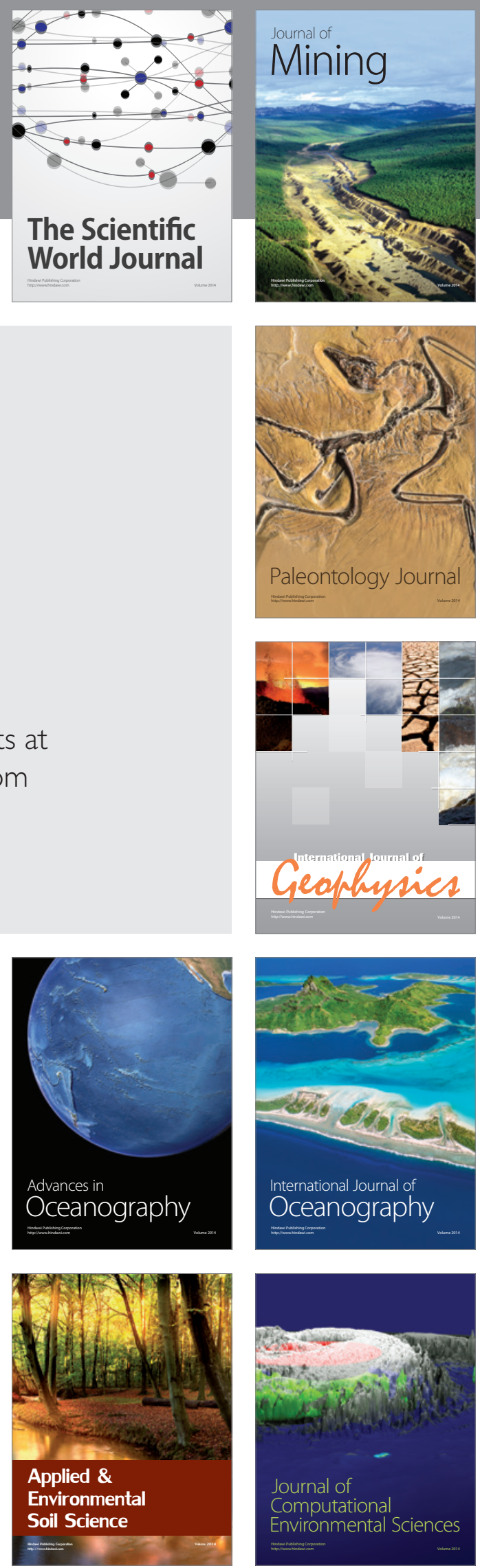